\title{
Semiotic engineering (i-system) thumb rule to fill the gap between formal principles \& practical realizations of textile, garment \& fashion technology
}

\begin{abstract}
Semiotic Engineering is the analysis of knowledge with a reverence to emphasize on cognitive psychology for system engineering to give a scientific approach in the hybrid domain of social engineering, cosmology (interoceptivity and exteroceptivity), humanities and sociology i.e. psychology, politics, growth of society and science of nature leading to modality by conglomeration of intuition, common sense, knowledge, expertise and experience resulting in $\mathrm{X}$-ability of product, process and ambience. ${ }^{1}$ The goal of ergonomics or human factor engineering or engineering psychology is to improve human's work activity with flexibility so it should be treated as the sub function of X-ability for process design however aesthetic attributes for product design respectively to avoid over functional chaos or exponential complexity. Multitasking of several modalities can be termed as 'Multimodality' or 'Conjoint Analysis Technique' based on the overall desirability of level of agreement with a reverence to emphasize on aesthetic attributes; ${ }^{2}$ Therefore, semiotics is applied by architecting the expert system with requirement engineering management to achieve multitude of good design i.e. $\mathrm{X}$ ability; it is based on scenario which consists of both engineering control system and physiological control system. Influencing factors can be quality based or quantity based; however, the focus is on engineering control system as it includes both; with an inspiration to move from conceptual model to mathematical model based on quantification. ${ }^{3}$
\end{abstract}

Keywords: fabric assurance simple testing, fabric ultimate requirement identification and optimizing universal system, i-style, i-fashion, i-handle, i-system
Volume I Issue 3 - 2017

\author{
Kanwar Varinder Pal Singh \\ Department of Textile Technology NIT Jalandhar, India
}

Correspondence: Kanwar Varinder Pal Singh, Department of Textile Technology, National Institute of Technology, G T Road Bye-Pass, Jalandhar, Punjab, India, Tel 01813082000 , Extension-3313, Fax 01812690324, Email singhkv@nitj.ac.in

Received: February 21, 2017 | Published: April 05, 2017
Abbreviations: FAST, fabric assurance simple testing; FAMOUS, fabric automatic measuring and optimizing universal system; FURIOUS, fabric ultimate requirement identification and optimizing universal system

\section{Introduction}

Semiotic engineering is a thumb rule to fill the gap between formal principles \& practical realizations of textile, garment \& fashion technology for product development. It is termed as an 'i-system' with co-evolution of both ' $\mathrm{i}$-fashion' and ' $\mathrm{i}$-handle' leading to 'level of agreement' for ultimate fabric identification for product development. ${ }^{4}$

In this Semiotic engineering (I-system) will be used for analysis of knowledge to make system engineering in Figure 1. Through conjoint analysis technique based on the overall desirability of level of thinking, understanding and agreement among social engineering, engineering psychology, sociology, mythology to achieve an X-ability with a reverence to emphasis on aesthetic attributes and inspiration to shift system from 'Physiological Control System' to 'Engineering Control System's in Figure 2.

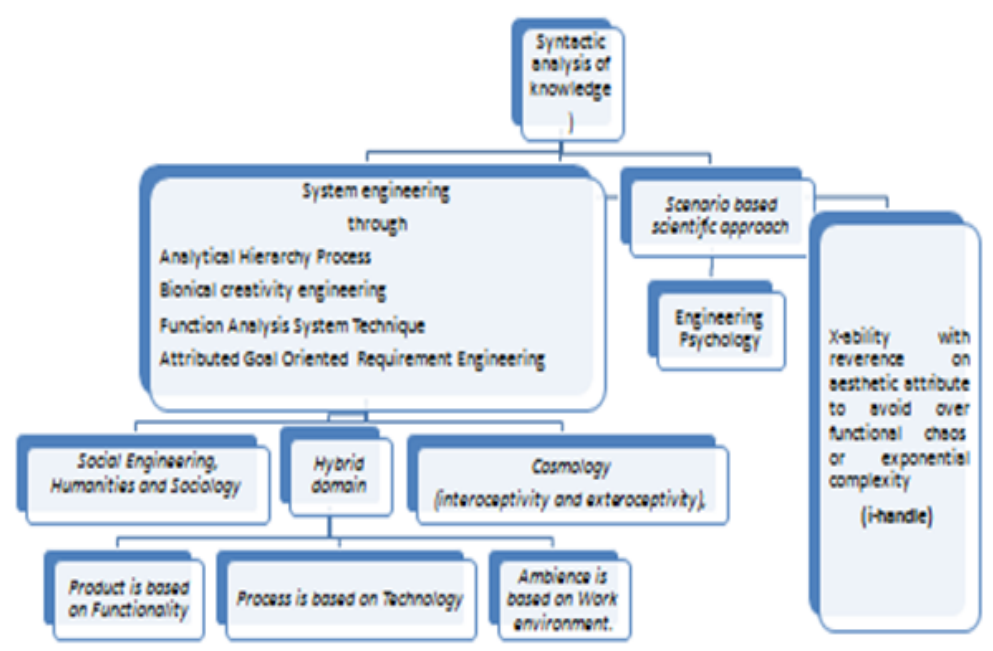

Figure I Flow shart of Semiotic Engineering. 
Fabric Assurance Simple Testing (FAST) is consisting of 10 parameters which will be handled for garment development with Function Analysis System Technique as per the functionality for ultimate fabric requirement identification leading to optimization for universal system better than Fabric Automatic Measuring and Optimizing Universal System (FAMOUS) which lacks ultimate requirement identification. ${ }^{6,7}$

These equipments are used for performance lab in product design. Modality of a designer in Figure 3 as per modesty is mentioned below for the Fabric ultimate requirement identification and optimizing universal system based clothing criteria and scenario considering requirement engineering management in Figure 4.,

\section{Design Research (DR)}

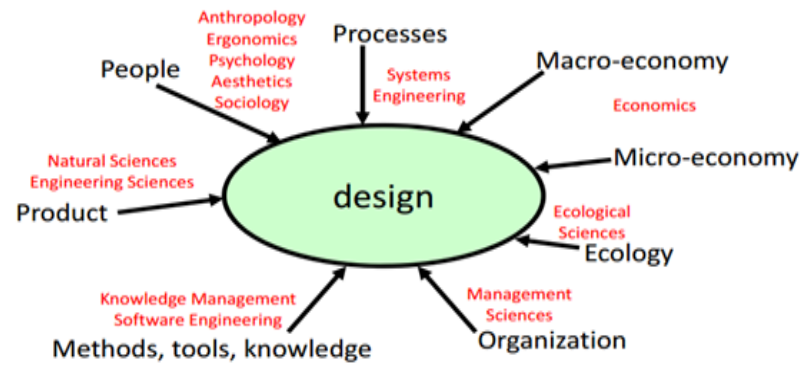

Figure 2 Broad base of Design methodology.
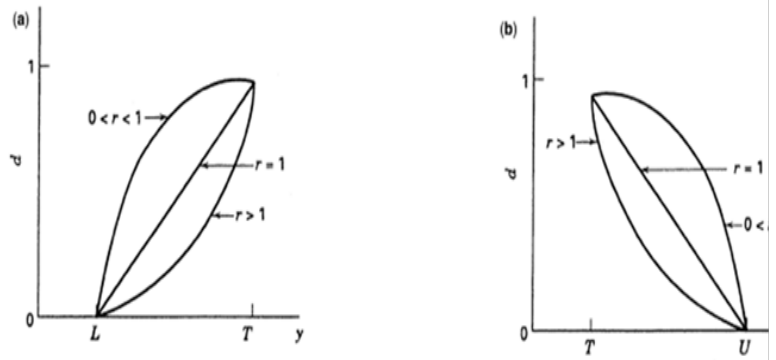

Consumers Perception

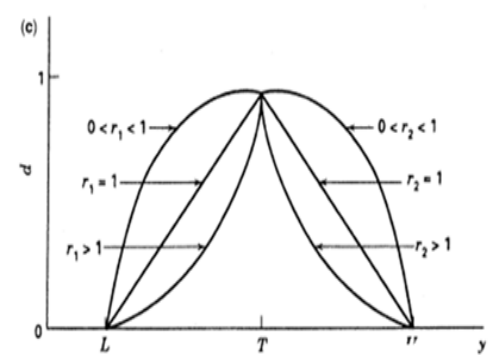

Modality for Fabric Ultimate Requirement Identification and Optimizing universal system

Figure 3 Desired modality of designer.

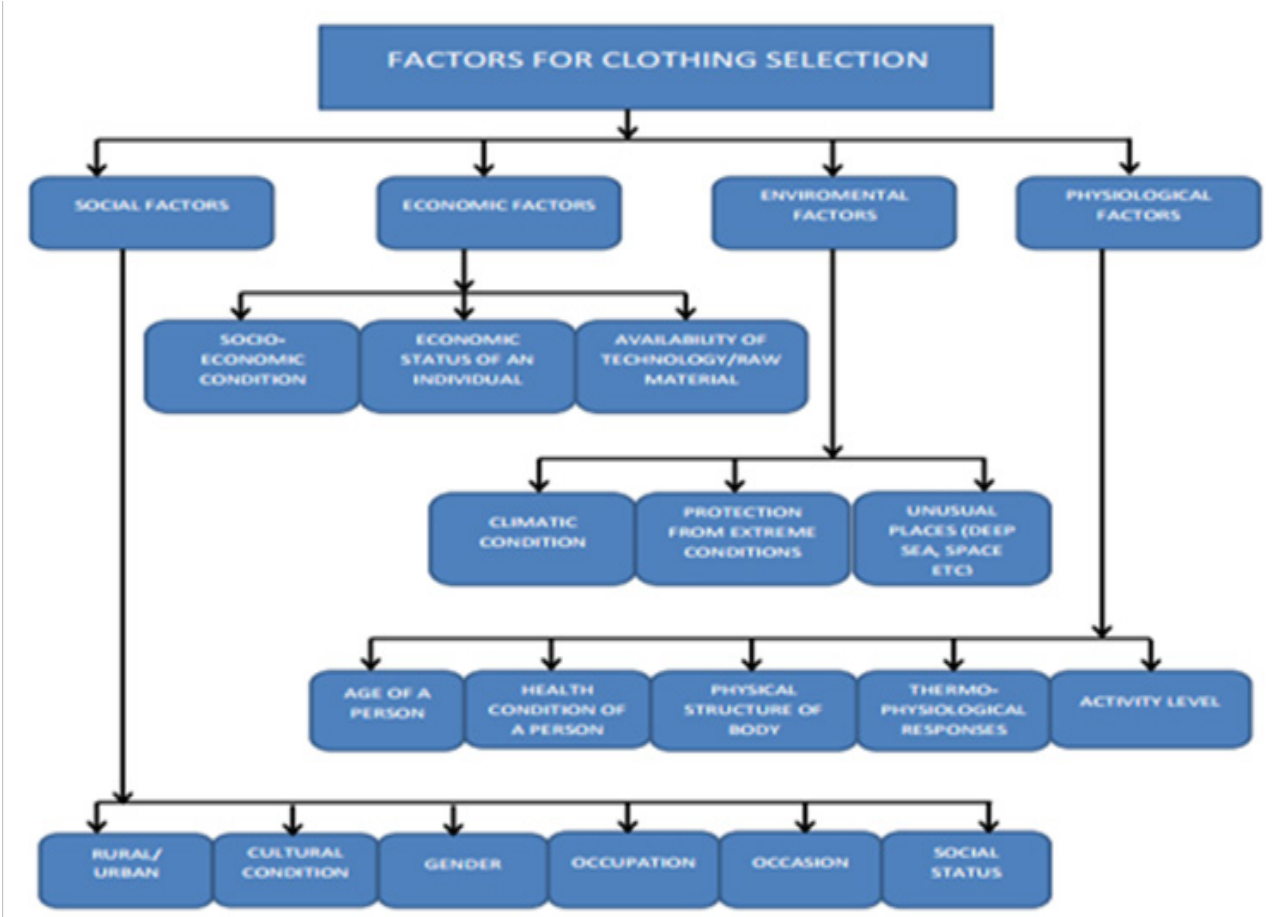

Figure 4 Broad factors for clothing selection.

\section{Conclusion}

As per the 3D body scanning technologies; ${ }^{10,11}$ I-styling or I-Fashion is a concept of optimizing in fashion industry with an emphasis on fashion however I-handle is a concept of simultaneous optimization of comfort and handle with an emphasis on technology.
Hybrid Domain with co-evolution of Level of agreement between fashion, style, comfort and handle is known as 'i-system'.

I-System is an interesting and realistic conclusion because it is beautiful, profound, stark and powerful but it is important to validate it as being adequate for the reality to fill the gap in a structural and 
systematic manner between formal principles and practical realizations rather than 'paradigmatic method' to match both consumer and designer perception and perspective.

\section{Acknowledgments}

None.

\section{Conflict of interest}

Author declares there is no conflict of interest in publishing the article.

\section{References}

1. Michael C K Khoo. Physiological control systems, Analysis, Simulation and Estimation, 1st ed. Prentice-Hall of India, New Delhi, India; 2005. p. $1-10$.

2. Sara Ilstedt Hjelm. Semiotics in product design. CID-175, University of Stock Holmes, Europe; 2002. p. 1-31.

3. Singh KVP, Das A, Chatterjee A. Quantification of the maximum desirability of physiological comfort of modified friction spun yarn. International Conference on futuristic trends in Textiles. National Institute of Technology. Punjab; 2007. p. 37.

4. Singh KVP, Das A, Fangueiro R. Quantification and optimization of overall desirability to achieve value added garment. University of MINHO, Campus De Azurem, India; 2014.
5. Singh KVP, Das A, Chatterjee A, et al. Improving friction yarn qualities for its use in foundation garments. Department of Textile Technology, Indian Institute of Technology, Delhi, India; 2014.

6. Singh KVP, Das A, Chatterjee A, et al. Improving friction yarn qualities for its use in foundation garments Part-2. School of Engineering, University of Minho, Portugal; 2014.

7. Singh KVP, Das A, Fanguiero R. Quantification and optimization of overall desirability to achieve value added garment. International Conference on Emerging trends in Traditional \& Technical Textiles. National Institute of Technology, Jalandhar, Punjab; 2014. p. 397-399.

8. Singh KVP. Aesthetic driven technology to achieve X-ability of product, process and ambience. ISTE Engineering Education Congress and National seminar on sustainability of engineering education. National Institute of Technology, Jalandhar, Punjab; 2015. p. 26-27.

9. Singh KVP, Chatterjee A, Das A, et al. Anthropometric study by diagnosing and antagonizing the feel factor of 'Ideal Fabric' with ' Reference Fabric' for frugal engineering of foundation garments. Process of 5th International Conference on 3D Body Scanning Technologies. Lugano, Switzerland; 2014. p. 414-421.

10. Arnold M. Une contribution possible de la semiotique .'al' intelligence artificielle, cognitive, CESTA, Paris; 1985.

11. Singh KVP. Semiotic engineering (i-system) thumb rule to fill the gap between formal principles \& practical realizations of textile, garment \& fashion technology. 2016. 